\title{
ANÁLISE DAS MUDANÇAS MORFOLÓGICAS COSTEIRAS DE MÉDIO PERÍODO NA MARGEM LESTE DA ILHA DE MARAJÓ (PA) EM IMAGEM LANDSAT
}

\section{CARMENA FERREIRA DE FRANÇA ${ }^{1}$ \& PEDRO WALFIR MARTINS E SOUZA FILHO²}

\begin{abstract}
ANALYSIS OF MID-TERM COASTAL MORPHOLOGICAL CHANGES FROM LANDSAT IMAGES, EASTERN MARAJÓ ISLAND, PARÁ Multi-date Landsat satellite data showed that during the last 15 years the coastal changes in the Eastern margin of the Marajó Island is mainly subject to retrograding processes. The retrograding areas compute $0.89 \mathrm{~km}_{2}^{2}(1986 / 1995), 0.381$ km2 (1995/1999) e $0.751 \mathrm{~km}^{2}(1999 / 2001)$; while prograding areas measure $0.214 \mathrm{~km}^{2}(1986 / 1995), 0.321 \mathrm{~km}^{2}(1995 / 1999)$ e 0.086 km2 (1999/2001). The coastal changes related to accretionary forms are associated to mangrove and beach-barrier development; while erosional features are related to mud terraces, coastal cliffs and mud deposits overlain by beach sands. Use of remote sensing in the study of the mid-term coastal changes constitutes one of the most important tools to record, monitor, map and compare areas in different sites and subject to shoreline retreat and accretion during the last decades.
\end{abstract}

Keywords: Remote sensing, coastal changes, mangroves.

\begin{abstract}
Resumo O estudo multitemporal das imagens de satélite Landsat mostrou que, durante os últimos 15 anos, a costa leste da Ilha de Marajóas esteve sujeita predominantemente a processos de recuo da linha de costa. As áreas retrogradacionais variaram de $0,89 \mathrm{~km}_{2}^{2}$ $(1986 / 1995)$ para $0,381 \mathrm{~km}^{2}(1995 / 1999)$ e $0,751 \mathrm{~km}^{2}(1999 / 2001)$, enquanto que as áreas progradacionais totalizaram $0,214 \mathrm{~km}$ $(1986 / 1995), 0,321 \mathrm{~km}^{2}(1995 / 1999)$ e $0,086 \mathrm{~km}^{2}(1999 / 2001)$. As variações costeiras relacionadas à acreção da linha de costa estiveram associadas ao desenvolvimento de manguezais e praias-barreiras, enquanto que as relacionadas à erosão apresentaram formações de terraços lamosos, falésias costeiras e migração de depósitos de duna-praia sobre manguezais. A aplicação do sensoriamento remoto e SIG, nos estudos das mudanças costeiras de médio período, constituiu uma das mais importantes técnicas para registrar, monitorar,mapear e comparar áreas em diferentes locais, sujeitas a recuo e acreção da linha de consta, nas últimas décadas.
\end{abstract}

Palavras-chave: Sensoriamento remoto, mudanças costeiras, manguezais.

INTRODUÇÃO As mudanças morfológicas costeiras consistem em um conjunto de transformações desencadeadas por processos naturais, que atuam em várias escalas temporais e espaciais, e se apresentam como crescimento ou diminuição de áreas de manguezais, desenvolvimento de cordões e bancos arenosos, recuos de falésias, migração de desembocaduras de canais de maré, etc. Essas mudanças são controladas pela ação interativa dos processos de maré, ondas e ventos, que causam erosão, transporte e sedimentação, de acordo com a configuração e orientação da costa, com os tipos de materiais que constituem os substratos costeiros, com a vegetação e com a presença de desembocaduras, refletindo uma resposta integrada do comportamento da costa aos processos e agentes dinâmicos (Santos 2000, Souza Filho 2000a, 2000b, Souza Filho \& Paradella 2002).

Dependendo da escala de observação, podem-se classificar mudanças de longo, de médio e de curto período. As primeiras e segundas são entendidas como mudanças progressivas, que correspondem a tendências acumulativas, envolvendo períodos de dezenas a milhares de anos, significando fases retrogradacionais ou progradacionais, ligadas à mobilidade sedimentar ao longo da costa, às flutuações relativas do nível do mar e a movimentos crustais de soerguimento ou subsidência costeira (Forbes \& Liverman 1996).

As mudanças de curto período referem-se a flutuações cíclicas, que ocorrem dentro de uma escala de tempo de dias a um ano, conforme a sazonalidade. Nesse caso, as mudanças podem estar relacionadas aos padrões cíclicos de freqüência e intensidade de tempestades, de alternância entre períodos úmidos e secos, de direção e intensidade dos ventos, de regime de ondas, de ocorrência de marés de sizígia, de transporte sedimentar e de balanço local de sedimentos (Nordstrom 1980).

Os geoindicadores são a base da análise das mudanças costeiras, fornecendo elementos para a mensuração e avaliação de processos e formas, que ocorrem em escalas de tempo de até 100 anos (Berger 1996). O mais importante geoindicador, adotado neste trabalho, foi a posição da linha de costa, tida como a linha de maré alta de sizígia, por ser considerado o mais preciso e o mais facilmente reconhecido em trabalhos de campo e em produtos de sensores remotos, utilizado principalmente para os estudos das zonas costeiras úmidas, dominadas por macro-marés, como a costa do Estado do Pará (Souza Filho 2000a, 2000b). Assim, a linha de maré alta de sizígia estabelece os limites da vegetação permanente de manguezais ou a interface destes com unidades morfológicas, tais como os cordões arenosos de praias e dunas, canais de maré, estuários, etc. O movimento da linha de costa fornece um registro da direção das mudanças e dos setores costeiros em erosão e acreção (Forbes \& Liverman 1996).

Diversos trabalhos utilizando técnicas de sensoriamento remo-

1 - Universidade Federal do Pará, Departamento de Geografia. Av. Augusto Corrêa 1, CP 1611, 66075-110, Belém-Pará. E-mail: carir@nautilus.com.br. 2 - Universidade Federal do Pará, Departamento de Geologia, Laboratório de análise de imagens do Trópico Úmido, Av. Augusto Corrêa 1, CP 1611, 66075-110, Belém-Pará. E-mail: walfir@ufpa.br 
to, para analisar variações da linha de costa de médio período, têm sido realizados para registrar, mapear, comparar e monitorar as diferentes posições dos limites das formas erosionais e acrecionais, ao longo do tempo. As mudanças dos limites e das formas podem ser compiladas, digitalizadas e manipuladas em Sistema de Informação Geográfica (SIG), sendo expressas em áreas, distâncias lineares, taxas e porcentagens (Gowda et al. 1995; Morton 1996; Souza Filho 2000b; Faure 2001).

O objetivo deste trabalho é, portanto, a análise multitemporal das mudanças costeiras, nos municípios de Soure e Salvaterra, na margem leste da Ilha de Marajó (Pará), durante os períodos de 1986-1995, 1995-1999 e 1999-2001, visualizadas a partir de produtos de sensores remotos ópticos, utilizando-se a variação da linha de costa como geoindicador.

MÉTODO DE TRABALHO A investigação baseou-se na comparação e análise de três imagens Landsat TM5 dos anos de 1986, 1995 e 1999, e uma imagem Landsat ETM+ 7 de 2001, abrangendo uma escala temporal de 15 anos. Detalhes das características das imagens podem ser observados na Tabela 1 .

Procedeu-se o tratamento e processamento digital das imagens orbitais com o Programa SPRING 3.5, desenvolvido pelo Instituto Nacional de Pesquisas Espaciais (INPE). As imagens foram geometricamente corrigidas, utilizando-se 15 pontos de controle, levantados em trabalho de campo, com auxílio do GPS Magelan 2000, obtendo-se um erro de 0,566 pixel.

Devido ao pequeno número de pontos de GPS, optou-se pelo registro das imagens Landsat 1986, 1999 e 2001 a partir da imagem 1995, selecionando-se 32 pontos de controle para cada registro, obtendo-se erros de $0,643,0,752$ e 0,715 pixel, respectivamente. Obteve-se a composição colorida com as bandas 3, 4 e 5, combinação 5R4G3B para todas as imagens utilizadas.

Com base nos erros dos pontos de controle e por simples regra de três, estabeleceu-se a margem de erro geométrico de cada imagem e o erro geométrico máximo cumulativo (Tabela 2).

Isso significa que, na análise dos dados 1986/1995, por exemplo, mudanças de até $1.088,1 \mathrm{~m}^{2}$ de áreas costeiras ou de até $36,27 \mathrm{~m}$ de distâncias lineares são desconsideradas ou tratadas como fora do limite de detecção dos sensores, interpretando-se como trechos estáveis ou sem mudanças aparentes. Da mesma forma, para os dados 1995/1999 e 1999/2001, adotaram-se os limites de até 1.186,2 $\mathrm{m}^{2}$ ou 39,54 m, e 1,320,3 $\mathrm{m}^{2}$ ou 44,01 m, respectivamente, como sendo limites do método, cujas variações não são detectadas.

Pela interpretação e digitalização visual, traçou-se para cada imagem os limites externos, delimitados pela linha de maré alta de sizígia (linha de costa), que corresponde: a) à linha de contato entre as planícies lamosas cobertas por manguezais e os cordões arenosos duna/praia; b) à linha limítrofe da planície de supramaré coberta por vegetação campestre com os cordões arenosos duna/ praia; e c) à linha de falésias em contato com os cordões arenosos praiais. A linha d'água ou de maré baixa foi utilizada apenas para identificar o contorno das desembocaduras e das praias-barreiras, nas imagens de 1986 e 1995.

Em seguida, foi feita a sobreposição dos vetores, a poligonalização, a classificação e quantificação das áreas progradacionais e retrogradacionais, das áreas de abrangência total dos manguezais, a mensuração de distâncias lineares e o cálculo de taxas e porcentagens de variações.

ÁREA DE ESTUDO A zona costeira dos municípios de Soure e Salvaterra está localizada na margem oriental da Ilha de Marajó,
Tabela 1 - Dados dos sensores utilizados e das condições de maré durante os imageamentos.

\begin{tabular}{lcccccc}
\hline Sensor & Satélite & $\begin{array}{c}\text { Órbita- } \\
\text { ponto }\end{array}$ & Data & $\begin{array}{c}\text { Resolução } \\
\text { espacial } \\
\text { (m) }\end{array}$ & Bandas & $\begin{array}{c}\text { Condições } \\
\text { de maré }\end{array}$ \\
\hline TM & LANDSAT 5 & $223-061$ & $17 / 07 / 1986$ & 30 & $5,4,3$ & Baixa \\
TM & LANDSAT 5 & $223-061$ & $08 / 06 / 1995$ & 30 & $5,4,3$ & Baixa \\
TM & LANDSAT 5 & $223-061$ & $13 / 07 / 1999$ & 30 & $5,4,3$ & Alta \\
ETM $^{+}$ & LANDSAT 7 & $223-061$ & $03 / 08 / 2001$ & 30 & $5,4,3$ & Alta \\
\hline
\end{tabular}

Tabela 2 - Erro geométrico de cada imagem com base nos erros dos pontos de controle.

\begin{tabular}{ccc}
\hline Ano da imagem & \multicolumn{2}{c}{ Erro geométrico } \\
& Por área $\left.\mathbf{( m}^{\mathbf{2}}\right)$ & Linear $\mathbf{( m )}$ \\
\hline 1986 & 578,7 & 19,29 \\
1995 & 509,4 & 16,98 \\
1999 & 676,8 & 22,56 \\
2001 & 643,5 & 21,45 \\
\hline
\end{tabular}

adjacente à Baía de Marajó (Fig. 1). A área em estudo é dominada por um regime de meso a macro-marés, cuja variação das marés de sizígia alcança valores máximos de 3,6 a 4,7 m, nas ilhas de Mosqueiro e dos Guarás, respectivamente (DHN 2001).

Com base na compartimentação morfológica, é possível distinguir dois tipos de costas. A costa alta de Salvaterra é formada pelo planalto costeiro, constituído por sedimentos terciários e quaternários do Grupo Barreiras/Pós-Barreiras, que dá origem a falésias de até $6 \mathrm{~m}$ de altura. A partir do sopé das falésias, estendem-se praias estreitas cuja zona de estirâncio possui larguras entre 33 e 85,7 m, e gradientes de 1:6,71 a 1:23,14, apresentando areias médias a grossas, moderadamente selecionadas. O planalto costeiro é seccionado por estreitos paleovales (de 200 a $1.500 \mathrm{~m}$ de largura), dentro dos quais se desenvolvem manguezais, nos trechos de influência das marés, ou planícies de supramaré com vegetação campestre, onde o regime é controlado pela pluviosidade e as marés só alcançam durante as sizígias. A linha de costa é demarcada pela base das falésias e pelos limites externos dos manguezais e dos campos, em contato com os cordões praiais.

A costa baixa de Soure, caracterizada por uma extensa planície costeira em posição longitudinal, com larguras que variam de 1.500 a $4.400 \mathrm{~m}$, formada por sedimentos quaternários lamosos e arenosos, de origem flúvio-marinha, coberta por manguezais que se alargam para norte. As praias são mais largas $(116,6$ a $423,4 \mathrm{~m}$, nas zonas de estirâncio), de gradientes mais suaves (1:48,4 a 1:109,75 nas zonas de estirâncio), e constituídas por areias finas bem selecionadas. A linha de costa é representada pelos limites dos manguezais com os cordões praiais (França 2003).

Na zona costeira de Soure e Salvaterra, identificam-se duas grandes unidades morfológicas: a) o Planalto Costeiro, coberto por vegetação de matas secundárias e capoeiras, e onde se instalou o sítio urbano de Soure e Salvaterra; e b) a Planície Costeira, que se subdivide em: terraços arenosos, planície lamosa de supramaré coberta por campos inundáveis, planície lamosa de intermaré coberta por manguezais, cordões arenosos antigos, cordões arenosos de dunas e praias atuais, canais de maré e deltas de maré vazante (França 2003).

RESULTADOS E DISCUSSÕES Os resultados da análise 


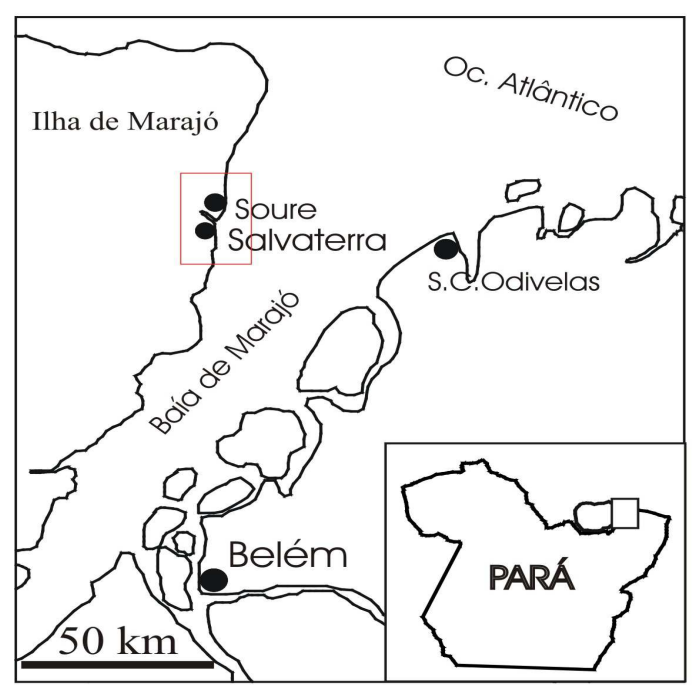

Figura 1 - Localização da área de estudo (cena TM Landsat-5 de 1995, composição colorida 5R4G3B).

multitemporal permitiram a caracterização, a quantificação e o mapeamento das mudanças costeiras de médio período, de Soure e Salvaterra, relacionadas aos avanços e recuos da linha de costa, à migração das principais desembocaduras e ao crescimento de praias-barreiras, entre 1986/1995, 1995/1999 e 1999/2001. As mudanças morfológicas foram classificadas em progradacionais e retrogradacionais.

Em função da divisão da zona costeira em unidades morfológicas, a análise das variações da linha de costa foi agrupada em três itens: a) interface manguezal - cordão arenoso duna/ praia (em Soure e Salvaterra); b) interface falésia - cordão arenoso praial (somente em Salvaterra); e c) interface campo - cordão arenoso duna/praia (somente em Salvaterra).

Variações da linha de costa INTERFACE MANGUEZAL-CORDÃOARENOSO DUNA/PRAIA Soure Em Soure, registraramse durante o período de 1986/1995 (9 anos) um total de $168.120 \mathrm{~m}^{2}$ de áreas progradacionais (19\% do total de áreas submetidas a mudanças costeiras), com avanço linear máximo da linha de costa calculado em $148 \mathrm{~m}$, à taxa máxima de $16 \mathrm{~m} / \mathrm{ano}$. A taxa média anual de progradação costeira foi de $18.680 \mathrm{~m}^{2} /$ ano. As áreas retrogradacionais totalizaram $727.804 \mathrm{~m}^{2}(81 \%$ do total de áreas submetidas a mudanças costeiras), com taxa de recuo da linha de costa de $80.867 \mathrm{~m}^{2} /$ ano, e distância linear máxima de $192 \mathrm{~m}$, que equivale à taxa de $21 \mathrm{~m} /$ ano. Na Figura 2, observam-se as áreas progradacionais e retrogradacionais, nos diferentes setores da costa de Soure. Os setores Araruna e Barra Velha-Garrote apresentaram as maiores áreas erosionais do período $\left(205.573 \mathrm{~m}^{2} \mathrm{e}\right.$ $215.890 \mathrm{~m}^{2}$, respectivamente).

Entre 1995/1999 (4 anos), a costa de Soure apresentou 266.275 $\mathrm{m}^{2}$ de áreas de progradação de manguezais ( $43 \%$ do total de áreas submetidas a mudanças costeiras), quando a linha de costa alcançou a distância máxima de $182 \mathrm{~m}$. A taxa de progradação foi de

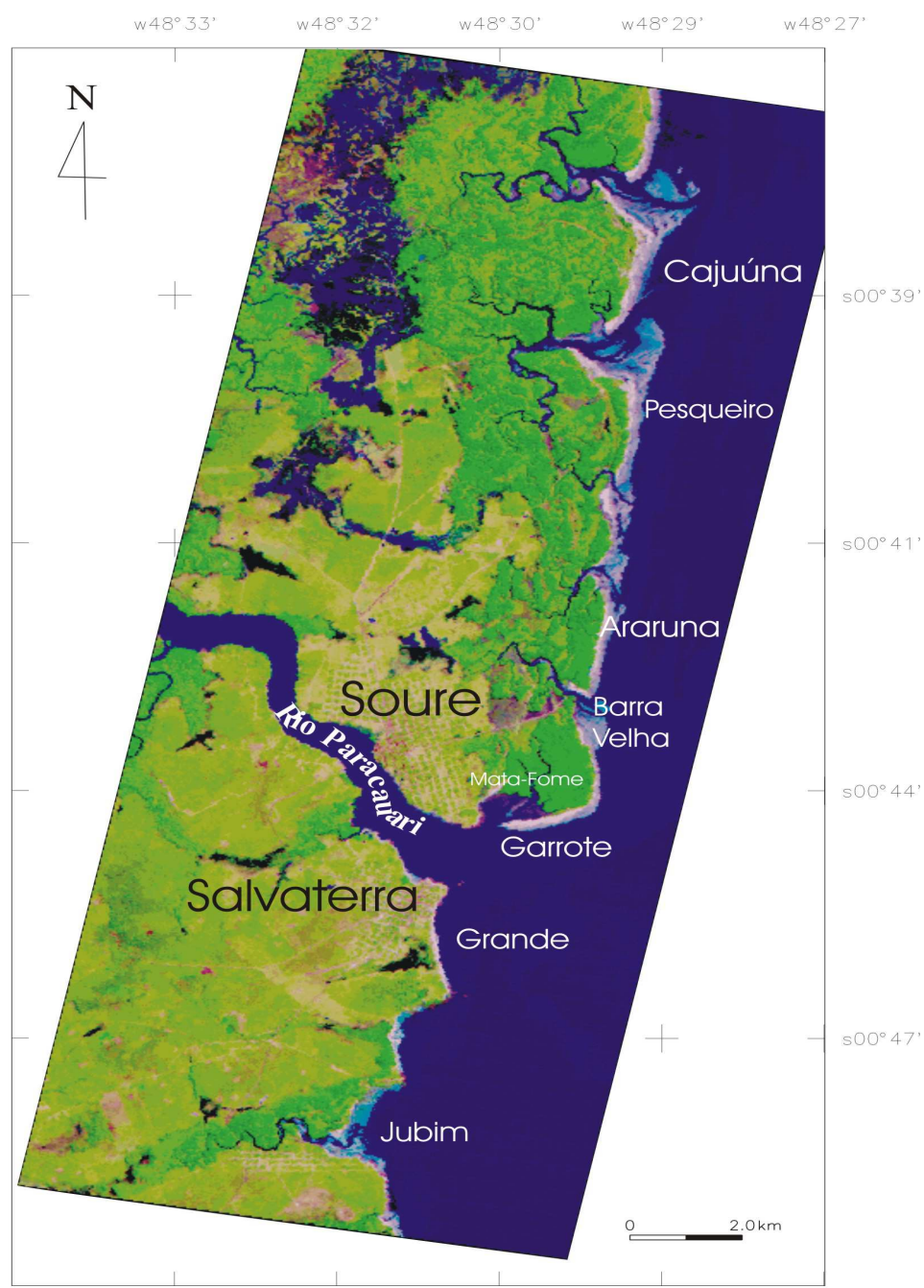

$66.568 \mathrm{~m}^{2} /$ ano e a taxa de avanço linear da linha de costa foi estimada em $45 \mathrm{~m} /$ ano. A área de maior crescimento de manguezais situou-se entre a praia do Garrote e o planalto costeiro, na porção sul de Soure, totalizando $159.620 \mathrm{~m}^{2}$, com taxa de crescimento de $109 \mathrm{~m} /$ ano. O total de áreas retrogradacionais chegou a $351.877 \mathrm{~m}^{2}$ ( $57 \%$ do total de áreas submetidas a mudanças costeiras), entre $1995 / 1999$, com taxa anual de $87.969 \mathrm{~m}^{2} /$ ano e recuo linear da linha de costa de 39 m/ano. Os setores Cajuúna e Barra Velha-Garrote mostraram as maiores áreas de retrogradação, isto é, $159.200 \mathrm{~m}^{2} \mathrm{e}$ $104.264 \mathrm{~m}^{2}$, respectivamente (Fig. 2).

De 1999 a 2001 (2 anos) apresentou $78.355 \mathrm{~m}^{2}$ de áreas de progradação de manguezais ( $10 \%$ do total de áreas submetidas a mudanças), com taxa anual de $39.177 \mathrm{~m}^{2} / \mathrm{ano}$, e as áreas de retrogradação de manguezais de $703.443 \mathrm{~m}^{2}$ (90\% do total de áreas submetidas a mudanças costeiras), e taxa anual de $351.721 \mathrm{~m}^{2} /$ ano. As taxas de avanço e recuo linear da linha de costa foram de 93 e 185 m/ano, respectivamente. Os setores Pesqueiro e Cajuúna apresentaram as maiores áreas erosionais $\left(184.788 \mathrm{~m}^{2}\right.$ e $\left.326.562 \mathrm{~m}^{2}\right)$ (Fig. 2).

Ao longo da costa de Soure, a distribuição das áreas progradacionais e retrogradacionais não foi uniforme, apresentando variações nos diferentes setores. Os setores Cajuúna (entre o canal do Cajuúna e o canal do Pesqueiro), Araruna (entre os canais da Glória e do Araruna) e Barra Velha/Garrote (entre o canal do Araruna e a praia do Garrote), mostraram as maiores áreas de 
erosão de manguezais, durante os últimos 15 anos. Essas áreas de recuo máximo da linha de costa estão relacionadas à posição dessas sub-regiões próximo à desembocadura de grandes canais de maré e à ponta de Soure, que são trechos da costa considerados de grande dinamicidade, devido à atuação de fortes correntes de maré e transporte de sedimentos.

Salvaterra Em Salvaterra, registraram-se, durante o período de 1986/1995, 18.326 m² de áreas de progradação de manguezais contra $124.243 \mathrm{~m}^{2}$ de áreas de retrogradação. Os manguezais progradaram à taxa de $2.036 \mathrm{~m}^{2} /$ ano e deslocaram a linha de costa em $62 \mathrm{~m}$. A taxa de retrogradação foi de $13.804 \mathrm{~m}^{2} /$ ano, com recuo máximo da linha de costa na ordem de $77 \mathrm{~m}$ à taxa de $8 \mathrm{~m} / \mathrm{ano}$.

Entre 1995 e 1999, as áreas progradacionais expandiram-se, chegando a $49.445 \mathrm{~m}^{2}$ diante de $2.340 \mathrm{~m}^{2}$ de áreas retrogradacionais. A taxa de avanço da linha de costa foi de $12.361 \mathrm{~m}^{2} /$ ano, e a distância linear máxima alcançada foi de $95 \mathrm{~m}$, representando $23 \mathrm{~m} / \mathrm{ano}$.

De 1999 a 2001, as áreas retrogradacionais alcançaram $42.162 \mathrm{~m}^{2}$, à taxa anual de $21.081 \mathrm{~m}^{2} /$ ano, contra $8.035 \mathrm{~m}^{2}$ do total de áreas progradacionais. O recuo máximo da linha de costa foi de $73 \mathrm{~m}$, equivalente à $36 \mathrm{~m} /$ ano (Fig. 3 ).

Os pulsos de variação da linha de costa, registrados como crescimento e diminuição de áreas progradacionais e retrogradacionais, relativos aos diferentes intervalos de tempo ( 9,4 e 2 anos), revelaram um brusco aumento da retrogradação de manguezais, nos últimos dois anos. O recuo linear dos manguezais, em Soure, apresentou taxas máximas anuais, que variaram de $21 \mathrm{~m} /$ ano (1986/ 1995) para 39 m/ano (1995/1999) e 185 m/ano (1999/2001). Enquanto que, em Salvaterra, as taxas lineares pularam de $8 \mathrm{~m} / \mathrm{ano}$ (1986/ 1995) para $36 \mathrm{~m} /$ ano (1999/2001). Esses valores quantificados demonstram um recrudescimento dos processos erosionais da linha de costa em toda a área de estudo, nos últimos anos.

INTERFACE FALÉSIA - CORDÃO ARENOSO PRAIAL Na costa de Salvaterra, cuja morfologia se caracteriza por um alinhamento de falésias esculpidas no planalto costeiro, registraram-se apenas recuos da linha de costa. No período 1986/1995, totalizaramse $34.988 \mathrm{~m}^{2}$ de áreas retrogradacionais, com taxa de $3.887 \mathrm{~m}^{2} /$ ano. O recuo máximo da linha de falésias chegou a $65 \mathrm{~m}$ ou $7 \mathrm{~m} / \mathrm{ano}$. Entre 1995/1999, não se registraram mudanças na linha de costa. Porém, em 1999/2001, totalizaram-se $6.331 \mathrm{~m}^{2}$ de áreas de falésias que foram erodidas, à taxa de $3.165 \mathrm{~m}^{2} / \mathrm{ano}$ (Fig. 3).

INTERFACE CAMPO-CORDÃOARENOSODUNA/PRAIA Em Salvaterra, a planície lamosa de supramaré coberta por campos estende-se desde os limites com os cordões de praias e dunas até os limites com o planalto costeiro, ocupando o interior de um paleovale. No período de 1986/1995, registraram-se $28.085 \mathrm{~m}^{2} \mathrm{de}$ áreas progradacionais, que diminuíram para $5.901 \mathrm{~m}^{2}$, em 1995/ 1999. Essa redução da progradação das áreas campestres referese à queda da taxa anual de $3.120 \mathrm{~m}^{2} / \mathrm{ano}(1986 / 1995)$ para $1.475 \mathrm{~m}^{2} /$ ano(1995/1999).

As áreas retrogradacionais apresentaram comportamento inverso, isto é, representavam em 1986/1995 apenas $3.460 \mathrm{~m}^{2}$, e aumentaram bruscamente para $26.866 \mathrm{~m}^{2}$, entre $1995 / 1999$. A taxa de retrogradação passou de $384 \mathrm{~m}^{2} /$ ano para $6.716 \mathrm{~m}^{2} /$ ano, respectivamente. O recuo máximo da linha de costa chegou a $167 \mathrm{~m}$, no período 1995/1999, à taxa de 41 m/ano. Entre 1999/2001, não se registraram recuo na área de campos (Fig. 3).

As flutuações sazonais da pluviosidade influenciaram sobremaneira no comportamento da vegetação campestre, no entanto, o adensamento da ocupação humana na zona de pós-praia e de duna, nesse trecho da costa de Salvaterra, foi o principal fator responsável pelas mudanças nos limites entre os campos inundáveis e o cordão duna/praia, nos últimos anos.

\section{Migração de desembocaduras de canais de maré e desenvolvi- mento de praias-barreiras Em Soure, as principais redes de} drenagem da planície costeira, representadas pelos canais do Cajuúna, Pesqueiro, Barco, Glória, Araruna e Uruci e, em Salvaterra, pelo canal do Jubim, apresentaram migração de suas desembocaduras, que foi analisada em imagens Landsat de 1986 e 1995, tomadas durante a maré baixa, o que permitiu melhor visualização dos contornos e do deslocamento de cada foz. Para a comparação dos movimentos das desembocaduras, foi utilizada a linha de maré baixa ou linha d'água, no momento da aquisição das imagens.

O canal do Cajuúna desaguava, em 1986, em uma única boca de direção SW-NE. Em 1995, este canal passou a desaguar em duas desembocaduras, uma no sentido SW-NE e outra W-E. Esta última foi resultado da migração da margem direita por cerca de $615 \mathrm{~m}$ para sul, equivalente a $68 \mathrm{~m} / \mathrm{ano}$, o que rompeu o delta de maré vazante na sua extremidade sul, dividindo-o em dois segmentos. O segmento norte permaneceu isolado do continente, durante a maré baixa, com ramificações para NE. O segmento sul ficou ligado à praia do Cajuúna, na maré baixa, e se alongou para E (Fig. 4A).

O canal do Pesqueiro, em 1986, vertia no sentido SW-NE e construía um delta que se estendia no sentido S-N. Em 1995, apresentou uma inflexão para norte, deslocando sua desembocadura cerca de $179 \mathrm{~m}$, à taxa de $19 \mathrm{~m} / \mathrm{ano}$, porém manteve a posição da foz no sentido SW-NE. O deslocamento relacionou-se ao crescimento longitudinal do delta para norte que, ao mesmo tempo, mudou sua forma, tornando-se mais estreito e recurvado para NW (Fig. 4B).

O canal do Barco fluia, em 1986, segundo N-S, e mudou a foz para NW-SE, em 1995, após uma migração de 896 m para norte, equivalente à taxa de $99 \mathrm{~m}$ ao ano. Isso diminuiu a extensão da praia do Pesqueiro, no trecho entre os canais do Pesqueiro e do Barco, de 3.188 m em 1986 para 2.292 m, em 1995 (Fig. 4C).

A migração do canal do Barco foi acompanhada pelo deslocamento do canal da Glória em sentido oposto. Em 1986, este canal desaguava na direção NW-SE, desenvolvendo um delta que se estendia nas direções W-E e N-S, devido ao seu efeito de barragem hidráulica para os sedimentos despejados ao norte pelo canal do Barco. Em 1995, o curso terminal do canal da Glória infletiu para para sul, deslocando-se $586 \mathrm{~m}$ ( isto é, $65 \mathrm{~m}$ ao ano), mas manteve a direção NW-SE da desembocadura. A migração do canal resultou no aumento da extensão da praia do Pesqueiro, no trecho entre os canais do Barco e da Glória, de 335 m, em 1986, para 1.901 $\mathrm{m}$, em 1995, correspondendo a uma taxa de crescimento de $174 \mathrm{~m} /$ ano. Os deslocamentos de ambos canais que seccionavam a praia do Pesqueiro, no período 1986/1995, associados à mobi-lização de sedimentos arenosos, nesse setor da costa, acabaram por ampliar a extensão total desta praia de $3.524 \mathrm{~m}$, em 1986, para $4.193 \mathrm{~m}$, em 1995, representando um crescimento de 74 m/ano (Fig. 4C).

Em 1986, o canal do Araruna vertia por uma única desembocadura, no sentido SW-NE, e desenvolvia um delta de maré vazante no sentido S-N. Em 1995, o canal bifurcou e rompeu o delta ao sul, abrindo uma segunda foz e desaguando em dois sentidos. A primeira desembocadura manteve o sentido SW-NE, após um deslocamento da margem esquerda de $112 \mathrm{~m}$ para noroeste, e a segunda posicionou-se para W-E, depois de uma migração da margem esquerda de $291 \mathrm{~m}$ para sul. A taxa de migração da margem esquerda foi de $12 \mathrm{~m} / \mathrm{ano}$, e da margem direita chegou a $32 \mathrm{~m} / \mathrm{ano}$, no período 


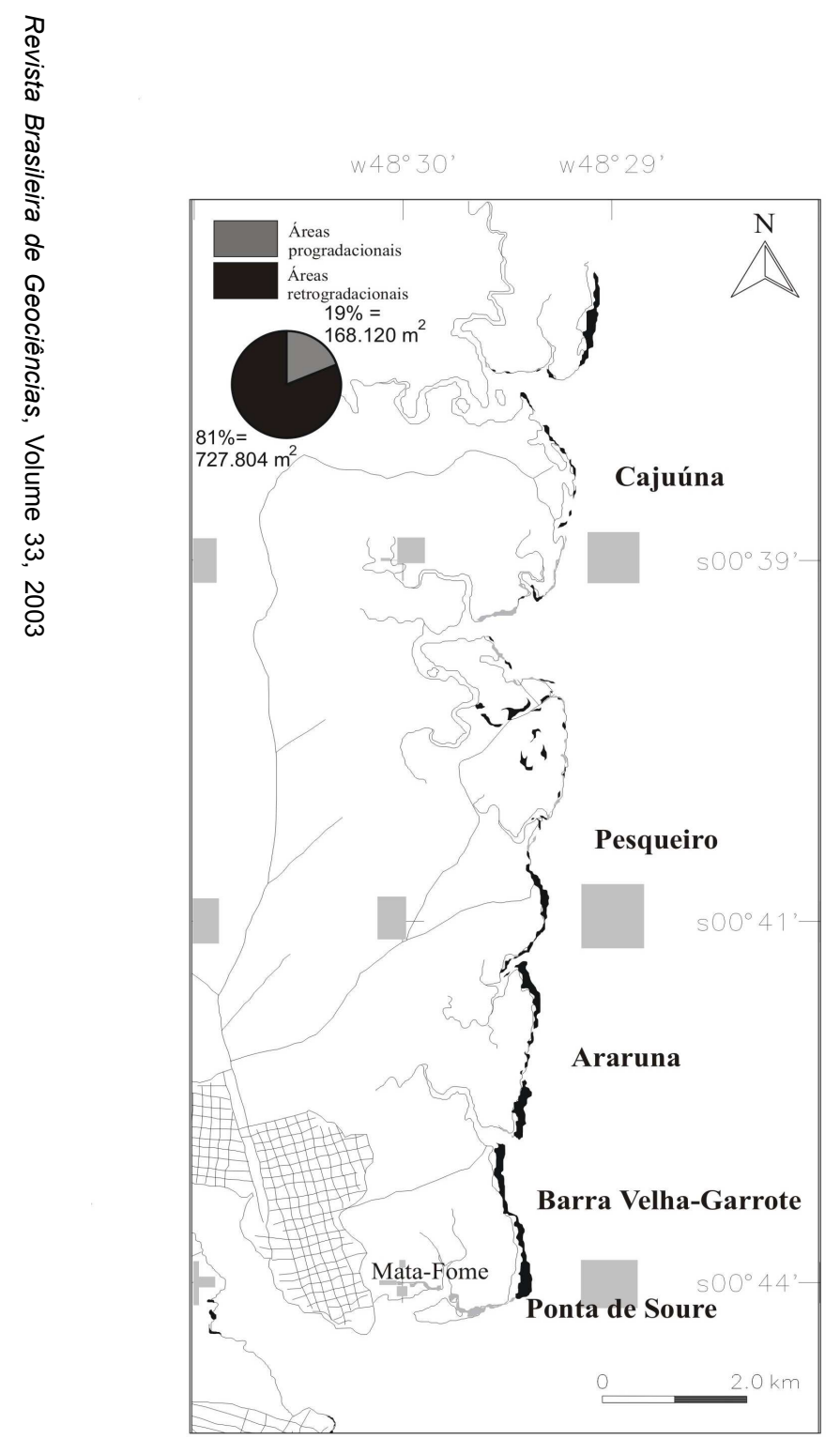

1986-1995

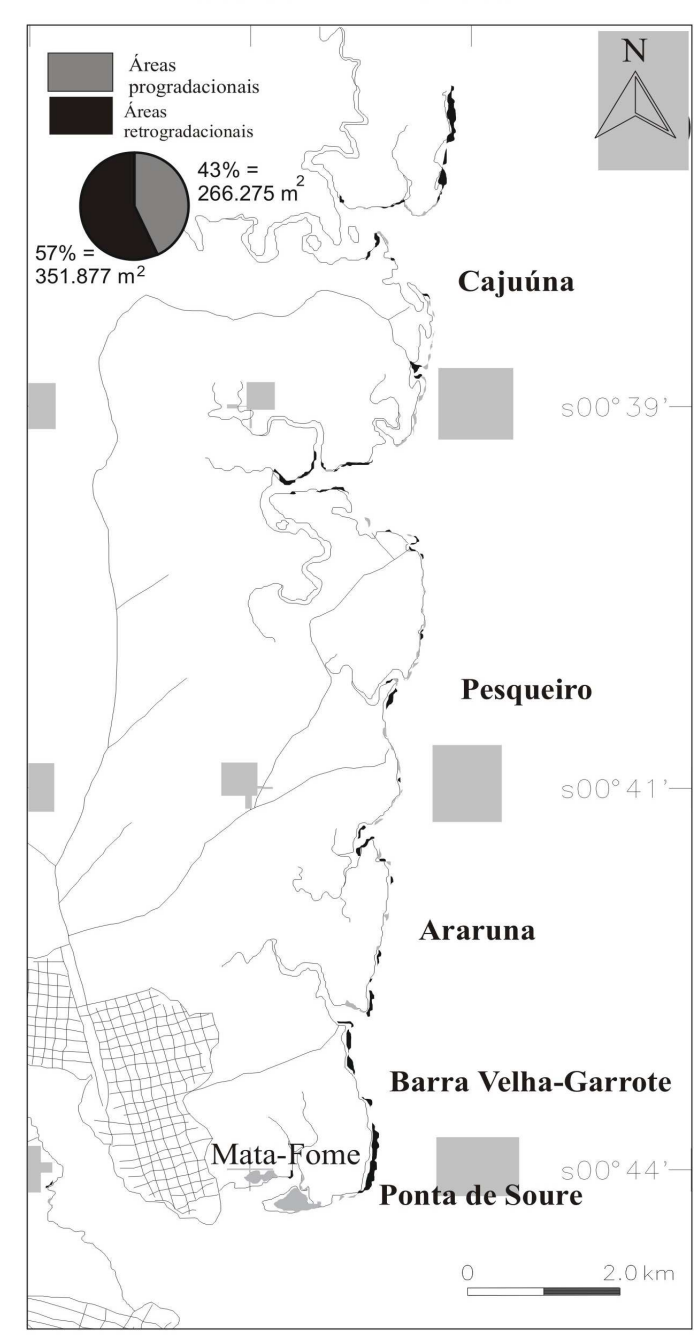

1995-1999

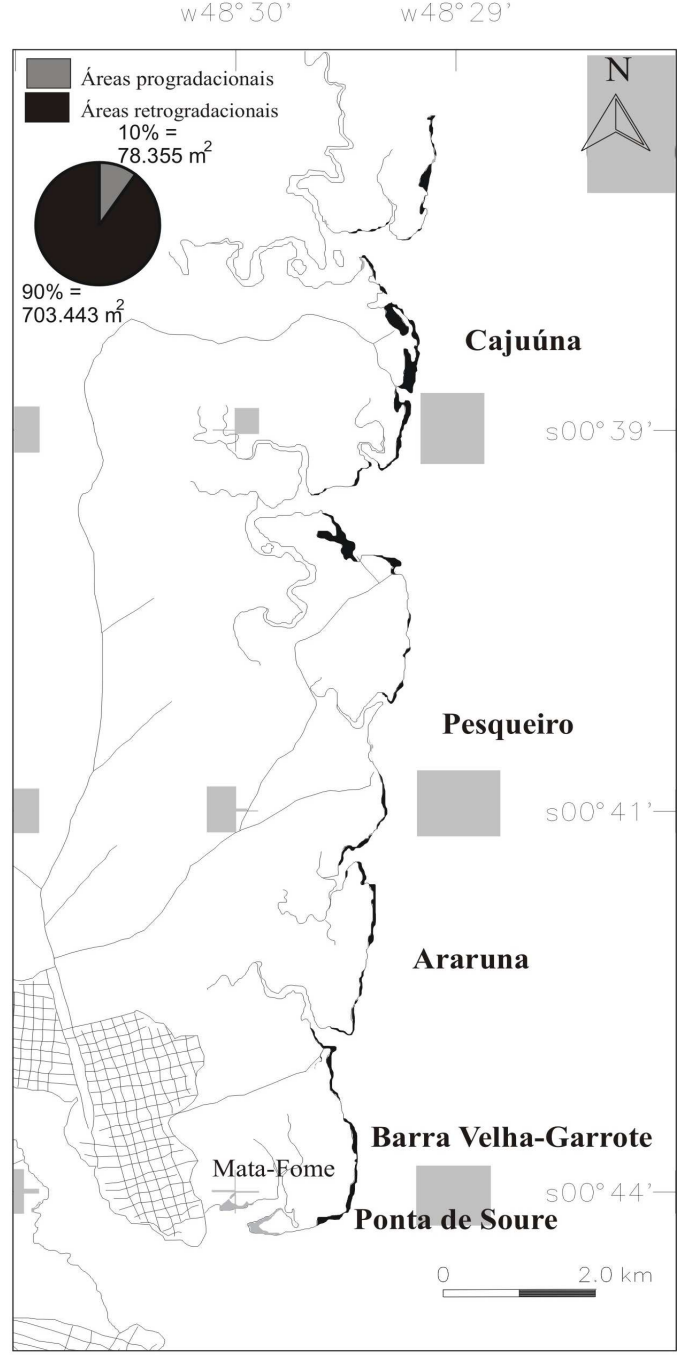

1999-2001

Figura 2 - Áreas progradacionais e retrogradacionais na interface manguezal/cordão duna-praia, da costa de Soure, entre 1986/1995, 1995/1999 e 1999/2001 

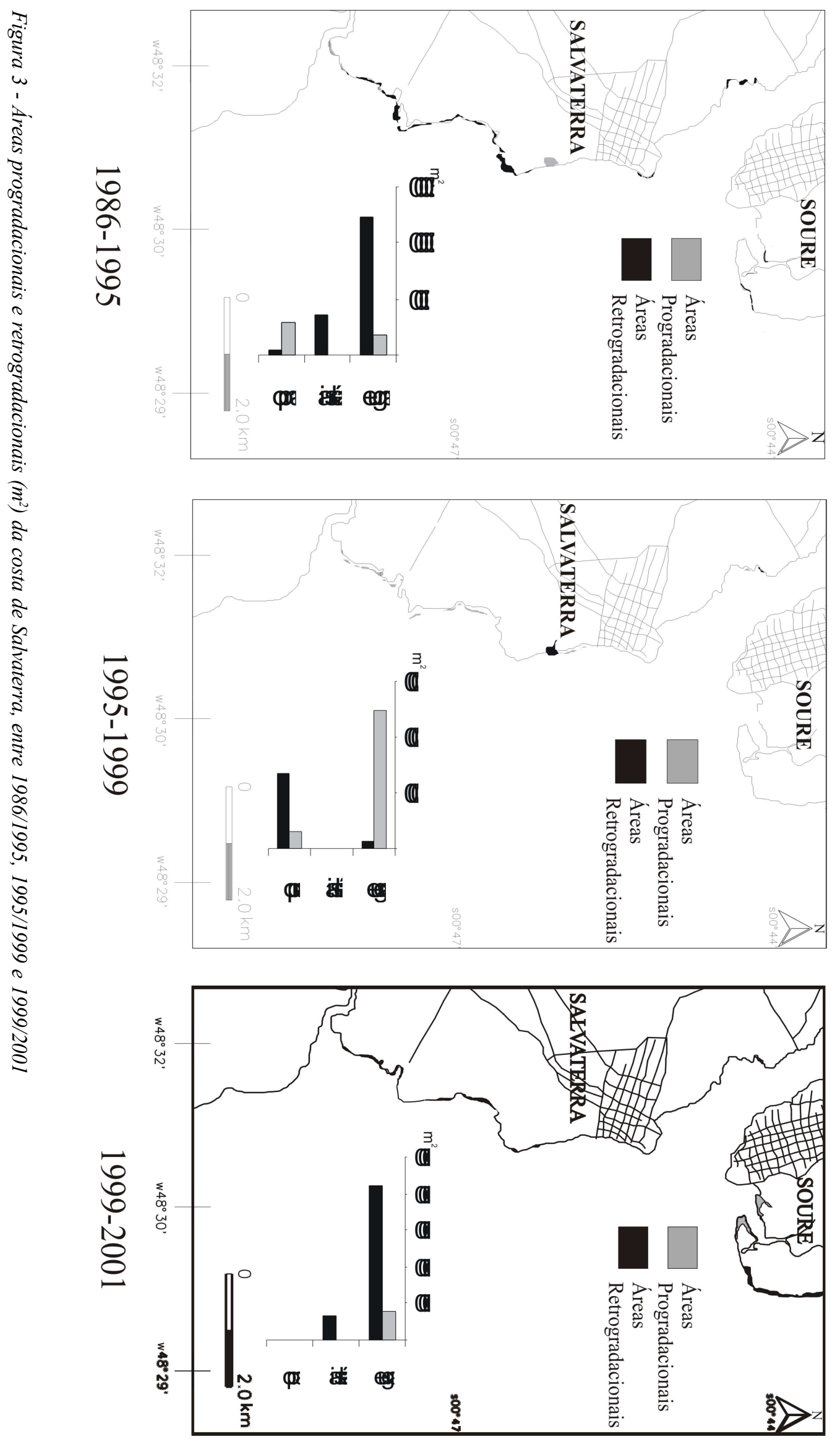


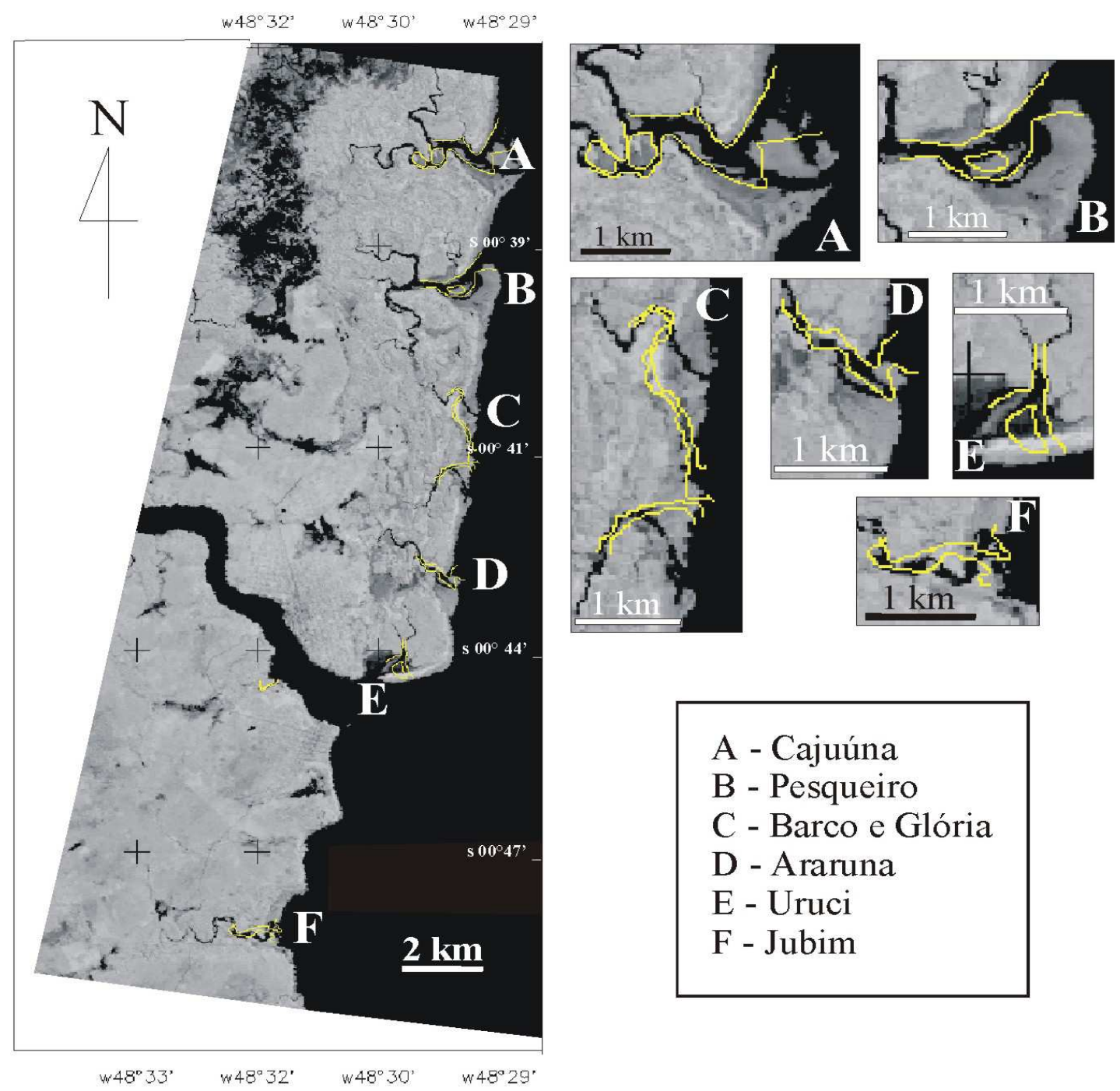

Figura 4 - Migração das desembocaduras dos principais canais de maré de Soure e Salvaterra, entre 1986 e 1995 (sobreposição do vetor 1986 à imagem 1995).

1986/1995. O deslocamento para sul seccionou o delta, gerando um segmento isolado e separando ambas desembocaduras. A migração do canal da Glória para $\mathrm{S}$ e do Araruna para NE reduziu a extensão da praia do Araruna de $2.751 \mathrm{~m}$, em 1986, para 2.137 m, em 1995, com uma taxa de $68 \mathrm{~m}$ /ano (Fig. 4D).

O canal do Uruci apresentava uma desembocadura bifurcada, em 1986, desaguando nas direções NE-SW e NNW-SSE, numa enseada na costa sul de Soure, entre o continente e a praia do Garrote. O crescimento desta praia-barreira, na direção oeste, fechou a desembocadura NNW-SSE e o canal passou a verter somente pela saída NE-SW, após um deslocamento de $174 \mathrm{~m}$ para oeste, à taxa de $19 \mathrm{~m}$ ao ano. A praia do Garrote expandiu-se de $1.516 \mathrm{~m}$ para $1.775 \mathrm{~m}$, no período $1986 / 1995$, à taxa de $28 \mathrm{~m} / \mathrm{ano}$, representando um aumento linear de $17 \%$ (Fig. 4E).

O canal do Jubim, em 1986, lançava-se no sentido NW-SE. Em 1995, infletiu para norte, mudando sua desembocadura para W-E, após um deslocamento de $254 \mathrm{~m}$, com taxa de migração de $28 \mathrm{~m} /$ ano. Ao mesmo tempo, desenvolveu um delta de maré vazante, no sentido S-N, com ramificações para SE e E (Fig. 4F).
A acreção e a erosão costeira resultam de alterações no suprimento sedimentar e nos processos costeiros, refletidas pela movimentação da linha de costa. Os processos acrecionais, relacionados a um maior aporte de areia e silte/argila, nos trechos mais protegidos do litoral, acarretam migração da linha de costa na direção do mar, permitindo, nos setores de sedimentação lamosa, a progradação da vegetação de mangues (Souza Filho 2000b).

Na margem esquerda da desembocadura do estuário Paracauari, na costa sul de Soure, o crescimento de um cordão arenoso, a partir da ponta de Soure para oeste, nos anos de 1986 a 2001, deu origem à praia-barreira do Garrote. Isso causou: a) formação de um sistema lagunar entre a praia-barreira e o continente; b) preenchimento por sedimentos arenosos e lamosos; c) abandono da crista da antiga praia do Mata-Fome em meio à planície de lama; d) Migração da desembocadura do canal do Uruci por cerca de $174 \mathrm{~m}$ para oeste; e e) crescimento de manguezais.

Em 1986, a flecha arenosa extendia-se por $1.516 \mathrm{~m} \mathrm{e}$, em 1995, alcançou $1.775 \mathrm{~m}$, crescendo $17 \%$ em 9 anos (Fig. 4). Hoje, estimase que o cordão chegue a $2.000 \mathrm{~m}$ de extensão, na maré baixa. É o 
Tabela 3 - Total de áreas progradacionais e retrogradacionais $\left(m^{2}\right)$, da costa de Soure e Salvaterra, nos intervalos de tempo 1986/ 1995, 1995/1999 e 1999/2001.

\begin{tabular}{|c|c|c|c|c|c|c|c|c|}
\hline \multirow{3}{*}{ Costa } & \multirow{3}{*}{ Inter-face } & \multirow{3}{*}{$\begin{array}{c}\text { Setor } \\
\text { costeiro }\end{array}$} & \multicolumn{6}{|c|}{ Intervalos de tempo $^{1}$} \\
\hline & & & \multicolumn{2}{|c|}{$1986 / 1995$} & \multicolumn{2}{|c|}{ 1995/1999 } & \multicolumn{2}{|c|}{ 1999/2001 } \\
\hline & & & Prograd. & Retrograd & Prograd. & Retrograd. & Prograd. & Retrograd \\
\hline \multirow{6}{*}{ Soure } & \multirow{6}{*}{$\begin{array}{l}\text { Mangue- } \\
\text { cordão } \\
\text { duna/ } \\
\text { praia }\end{array}$} & Cajuúna & $58.571,36$ & $182.908,8$ & $41.793,87$ & $159.200,45$ & $10.264,86$ & $326.562,87$ \\
\hline & & Pesqueiro & $21.965,81$ & $123.431,91$ & $42.497,23$ & $46.041,48$ & $1.428,06$ & $184.788,46$ \\
\hline & & Araruna & $5.026,66$ & $205 . .573,95$ & $22.364,14$ & $39.045,16$ & - & $75.352,68$ \\
\hline & & B.V-Garrote & $59.362,62$ & $215.890,0$ & $113.254,0$ & $104.264,09$ & $37.040,12$ & $116.739,5$ \\
\hline & & Mata-Fome & $23.194,37$ & & $46.366,03$ & $3.326,14$ & $29.622,78$ & \\
\hline & & Total $\left(\mathbf{m}^{2}\right)$ & $168 . .120$ & $727 . .804$ & $266 . .275$ & 351..877 & 78.355 & 703.443 \\
\hline \multirow{3}{*}{ Salvaterra } & $\begin{array}{l}\text { Mangue- } \\
\text { cordão } \\
\text { duna/ } \\
\text { praia }\end{array}$ & 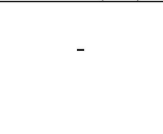 & $18.326,04$ & $124.243,93$ & $49.445,66$ & $2.340,08$ & $8.035,46$ & $42.162,9$ \\
\hline & $\begin{array}{l}\text { Falésia- } \\
\text { cordão } \\
\text { praial }\end{array}$ & - & - & $34.988,14$ & - & - & - & $6 . .331,64$ \\
\hline & $\begin{array}{l}\text { Campo- } \\
\text { cordão } \\
\text { praial }\end{array}$ & - & $28.085,26$ & $3.460,2$ & $5.901,59$ & $26.866,96$ & - & - \\
\hline \multicolumn{9}{|c|}{$\begin{array}{c}\text { Erros geométricos na quantificação das área } \\
\quad>\quad \text { Intervalo } 1986 / 1995: \pm 1.088,1 \mathrm{~m}^{2} \\
>\text { Intervalo } 1995 / 1999: \pm 1.186,2 \mathrm{~m}^{2} \\
\text { Intervalo } 1999 / 2001: \pm 1.320,3 \mathrm{~m}^{2}\end{array}$} \\
\hline
\end{tabular}

setor costeiro de maior progradação da linha de mangue e de acreção sedimentar de Soure, chegando à distância linear máxima de 138 m, entre 1999 e 2001, à taxa de 69 m/ano. Porém, a taxa máxima de progradação de manguezais, nesse setor costeiro, ocorreu no período 1995/1999, quando alcançou a acreção linear máxima de $438 \mathrm{~m}$, com taxa de $109 \mathrm{~m}$ ao ano, correspondendo a cerca de $60 \%$ do crescimento dos últimos 15 anos (Fig. 2).

As feições morfológicas resultantes da acreção sedimentar, nesse trecho da costa, são representadas principalmente pela praia-barreira e pelos bancos lamosos. Estes desenvolvem uma vegetação pioneira de mangues, constituída principalmente pelas espécies Avicennia sp. e Laguncularia sp, além de Spartina sp. associada. Essas espécies contribuem, por sua vez, para o processo geomorfológico de progradação, atuando como fixadoras de sedimentos, e apresentam padrões de sucessão vegetacional, chamados de "cogumelo" e "escada" (Prost et al. 2001). O padrão "cogumelo" exibe uma distribuição concêntrica de espécies vegetais, e o padrão "escada" mostra estratos de espécies pioneiras, sucedidos por bosques jovens e bosques adultos (Fig. 5).

Nos setores costeiros com pouco suprimento sedimentar, os processos erosionais produzem o deslocamento da linha de costa para o continente, recuando os limites dos manguezais ou das falésias. Os processos sedimentares atuantes acarretam o avanço dos cordões arenosos de praias e dunas sobre os depósitos lamosos de manguezais. Próximo às desembocaduras de estuários e canais de maré, a erosão dos manguezais é controlada pela migração dessas desembocaduras e dos bancos arenosos (Souza Filho 2000b). A erosão da linha de manguezais por correntes de maré e ondas, e o assoreamento causado pelas areias praiais, acarretam a morte, o ressecamento e o tombamento de árvores do mangue, apresentando o padrão "paliteiro" (Prost et al. 2001).

Os limites dos manguezais de Soure com os cordões de dunas e praias, no trecho desde a praia do Cajuúna até a praia do Garrote, numa extensão de aproximadamente $14 \mathrm{Km}$, e em Salvaterra, nos limites das falésias, mangues e campos com as praias, numa extensão de $5 \mathrm{Km}$, caracterizam-se por taxas crescentes de retrogradação, controladas pela dinâmica da Baía de Marajó.

As feições morfológicas resultantes da erosão costeira são: a) os terraços de lama de 0,5 a $1 \mathrm{~m}$ de altura, que se formam na zona de contato dos manguezais com as praias, devido à morte e queda das árvores, às alterações pedogênicas do substrato e ao solapamento pelas ondas, e b) as falésias cujo desmantelamento progressivo gera escarpas de até $6 \mathrm{~m}$ de altura, bancos de cascalhos e blocos rolados (Fig. 6).

A comparação das imagens Landsat, entre 1986 e 2001, revelou também uma diminuição da área total dos manguezais. Em Soure, os manguezais diminuíram de $37 \mathrm{~km}^{2}$, em 1986, para $26 \mathrm{~km}^{2}$, em 2001 , representando uma redução de $10 \mathrm{~km}^{2}$ nos últimos 15 anos. Em Salvaterra, a área total dos manguezais reduziu-se de $3 \mathrm{~km}^{2}$, em 1986 , para $2,8 \mathrm{~km}^{2} \mathrm{em} 2001$, equivalentes à perda de $0,22 \mathrm{~km}^{2}$. As taxas mostraram reduções anuais de $0,72 \mathrm{~km}^{2} /$ ano, para a costa de Soure, e de $0,01 \mathrm{~km}^{2} /$ ano para a costa de Salvaterra.

A configuração costeira exerceu influência na extensão e intensidade dos processos. Os padrões naturais de erosão e sedimentação, que condicionam a morfologia e a posição da linha de costa, mostraram diferenças entre Soure e Salvaterra em função da própria diversidade fisiográfica. Apesar do predomínio dos processos retrogradacionais sobre os progradacionais, a extensão e a altimetria do planalto costeiro, em Salvaterra, proporcionou uma maior estabilidade e proteção à zona costeira, enquanto que, em Soure, a área maior e o baixo gradiente da planície costeira, que tornaram essa região mais propensa à inundação, à mobilidade sedimentar e às mudanças topográficas, responderam pela maior magnitude e intensidade das mudanças, relacionadas principalmente à erosão da linha de costa, controlada por fatores eminentemente naturais ligados à dinâmica da Baía de Marajó.

A aplicação do sensoriamento remoto, utilizando imagens de diferentes épocas, produzidas por sensores ópticos, como ferramenta para qualificar e quantificar as variações da linha de costa, tornou-se indispensável para o registro, o mapeamento e a comparação das diferentes posições das formas progradacionais e retrogradacionais, ao longo do tempo. Além de permitir que as mudanças costeiras fossem avaliadas, considerando-se os aspectos de direção, abrangência, intensidade e freqüência.

Trabalhos futuros, utilizando dados de radar de abertura sintética (SAR), podem trazer novas informações sobre a dinâmica sa- 

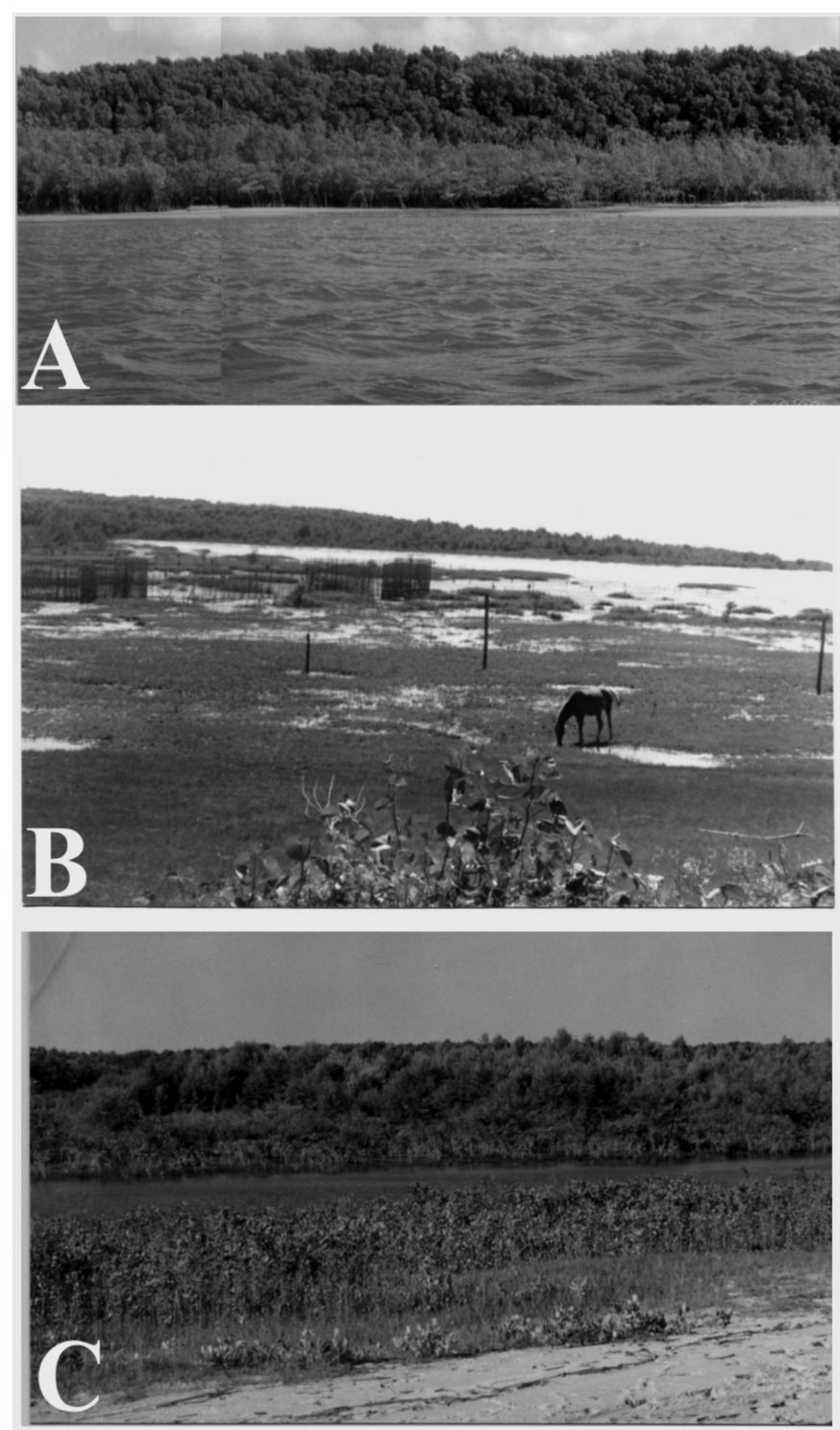

Figura 5 - Processos e feições morfológicas decorrentes da acreção costeira: A e B) crescimento de bancos lamosos com vegetação pioneira de mangues e mangues jovens; $C$ ) crescimento de praia-barreira.

zonal da linha de costa, devido à capacidade de imageamento sob condições de tempo adversas, uma vez que os sensores ópticos não permitem a aquisição de informações durante a estaçãochuvosa, que se estende de dezembro a maio.

CONCLUSÕES Os processos naturais atuantes caracterizaram a costa de Soure e Salvaterra, no trecho compreendido entre o Canal do Cajuúna e o canal do Jubim, abrangendo uma extensão de 23,5 Km, como uma costa retrogradacional, nos últimos 15 anos. As mudanças morfológicas foram classificadas e analisadas a partir da interpretação de imagens Landsat, dos anos de 1986, 1995, 1999 e 2001.

O sensoriamento remoto, associado ao Programa SPRING 3.5, permitiu o mapeamento dessas mudanças, expressas em áreas progradacionais e retrogradacionais, a identificação da direção e
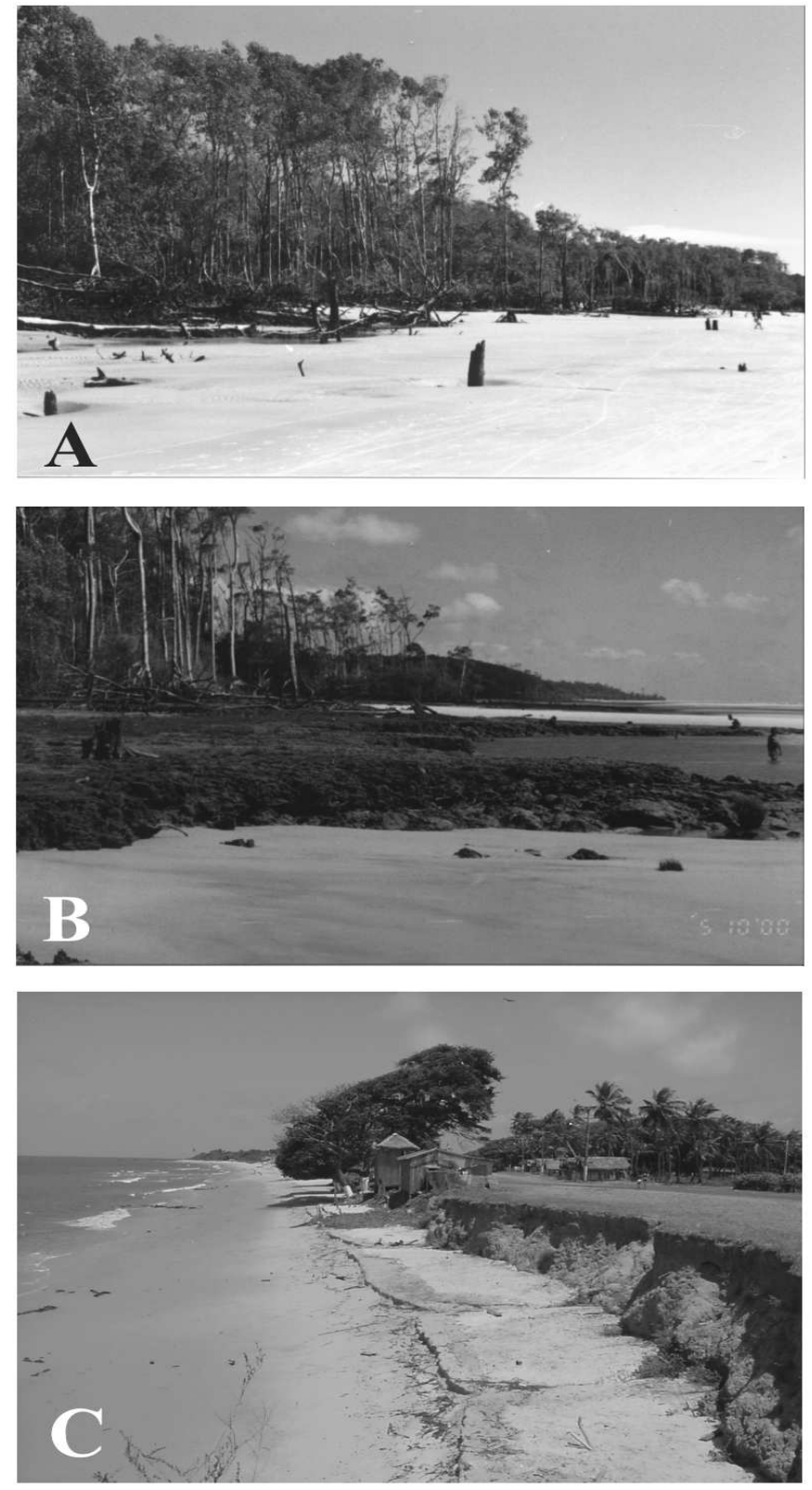

Figura 6-Processos e feições morfológicas decorrentes da erosão costeira: A) recuo da linha de manguezais e migração de cordões arenosos sobre depósitos de manguezais; B) formação de terraços de lama; e C) formação de falésias do Grupo Barreiras/Pós-Barreiras.

da distribuição espacial das mudanças, bem como a quantificação dos setores costeiros sujeitos à erosão e à acreção.

A ocorrência de zonas de progradação e retrogradação costeira relacionou-se à movimentação da linha de costa ou linha de maré alta de sizígIa, representada pelo limite dos manguezais, falésias e campos com os cordões arenosos de praias e dunas. A migração de desembocaduras de canais de maré e o desenvolvimento de praias-barreiras foram também considerados como mudanças costeiras, baseadas na movimentação da linha d'água, somente nas imagens de 1986 e 1995. Porém, a linha de costa foi utilizada como o principal indicador geomorfológico na caracterização das mu- 
danças costeiras de médio período.

Pela comparação das imagens orbitais e pelas observações de campo, identificaram-se os três setores da costa, onde as mudanças foram mais relevantes, entre 1986 e 2001:

$\left.1 .^{\circ}\right)$ na costa sul de Soure, o desenvolvimento da praia-flecha barreira do Garrote fechou uma antiga enseada e proporcionou a formação de um sistema lagunar, onde predominou a sedimentação lamosa e a progradação de manguezais, perfazendo um total de $0,308 \mathrm{~km}^{2}$ de áreas acrecionais, com taxa de $0,02 \mathrm{~km}^{2} /$ ano. A progradação lamosa acarretou a migração da foz do canal do Uruci para oeste e abandono da antiga crista praial do Mata-Fome. Foi o setor costeiro de maior avanço da linha de costa;

$\left.2 .^{\circ}\right)$ na costa oriental de Soure, nas zonas de contato entre os manguezais e as praias do Cajuúna, Pesqueiro, Araruna, Barra Velha e Garrote, expostas à ação das ondas e correntes de maré da Baía de Marajó, observaram-se: a) migração dos depósitos arenosos praiais e/ou dunares sobre os depósitos lamosos de manguezais, gerando recuo da linha de costa; b) morte e queda da franja de mangues; c) formação de terraços lamosos; e d) deslocamento das principais desembocaduras para norte ou para sul, definindo saídas nas direções NE, E e SE . Foi uma região caracterizada pela maior retrogradação costeira, totalizando $1,78 \mathrm{~km}^{2}$ de áreas erodidas, à taxa de $0,118 \mathrm{~km}^{2} / \mathrm{ano}$;

3.') nas falésias de Salvaterra, o solapamento pelas ondas e o desmoronamento pelas chuvas acarretaram a erosão progressiva das mesmas, gerando formas escarpadas de até $6 \mathrm{~m}$ de altura, bancos de cascalhos e blocos rolados, influenciando na granulometria dos sedimentos praiais. Este trecho da costa foi marcado pela retrogradação do planalto costeiro, que também atingiu diretamente a parte leste da cidade de Salvaterra, com perda de ruas e propriedades. Estimou-se que o recuo da linha de falésias atingiu uma área de $0,041 \mathrm{~km}^{2}$, à taxa de $0,002 \mathrm{~km}^{2} /$ ano.

A análise multitemporal revelou que, além da movimentação da linha de costa, houve mudanças na linha limítrofe interna dos manguezais, em contato com a planície aluvial e com o planalto costeiro, no interior da zona costeira de Soure e Salvaterra. A mobilidade dos limites internos na direção da costa foi acompanhada provavelmente pela migração de depósitos continentais (planície aluvial com vegetação campestre) sobre ambientes de mangue. Para uma compreensão mais efetiva das mudanças morfológicas internas e externas, é necessário que novas investigações sejam realizadas somando-se, aos dados já existentes, o monitoramento dos processos gerados por marés, correntes e ondas, da dinâmica sedimentar e dos possíveis impactos induzidos pelo uso e ocupação da costa.

Agradecimentos Este trabalho faz parte da tese de doutorado do primeiro autor, vinculado ao Curso de Pós-Graduação em Geologia e Geoquímica (CPGG), da Universidade Federal do Pará(UFPA). Agradecemos, em especial, à Unidade de Análises Espaciais (UAS), do Museu Paraense Emílio Goeldi (MPEG), pela concessão das imagens Landsat, ao Laboratório de Análise de Imagens do Trópico Umido (LAIT), do Centro de Geociências (UFPA), ao CNPq pela bolsa de produtividade em pesquisa concedida ao segundo autor. Gostaríamos de agradecer também aos técnicos Lourival Júnior e Helenice Silva, aos colegas Fábio Colares e Francisco Costa pelo auxílio no tratamento e processamento das imagens pelo Programa Spring, e ao geólogo Rafael Nascimento (MPEG) pela concessão de fotografias das falésias de Salvaterra. Aos revisores da RBg pelas sugestões ao manuscrito.

\section{Referências}

Berger A.R. 1996. The geoindicator concept and its application: na introduction. In: R.B. Antony \& J.I William J. Iams (ed.). Geoindicators. assessing rapid environmental changes en earth systems. Rotterdam, A.A. Balkema, pp. 1-14.

Diretoria de Hidrografia e Navegação (DHN). 2001. Tábua das Marés para 2001 (Ilha de Mosqueiro e Ilha dos Guarás). Marinha do Brasil. Rio de Janeiro.

Faure J-F. 2001. Multitemporal analysis of mangrove spatial dynamics in São Caetano de Odivelas, Pará, Brazil. In: M.T. Prost \& A.C. Mendes (ed.). Ecossistemas costeiros: impactos e gestão ambiental. Belém: Museu Paraense Emílio Goeldi, p. 39-49.

Forbes D.L. \& Liverman D.G.E. 1996. Geological indicators in the coastal zone. In: A.R. Berger \& W.J. Iams (ed.). Geoindicators: assessing rapid environmental changes in earth systems. Rotterdam: A.A.Balkema, p. 175-192.

França C.F. 2003. Morfologia e mudnças costeiras da margem leste da Ilha de Marajó (PA). Tese de doutorado, Centro de Geociências, Universidade Federal do Pará, 144 pg.

Gowda H.H., Raj K.G., Padmavathy A.S., Manikiam B. 1995. Multidate satellite data for study of dynamics of coastal landforms of Uttara Kannada, South India. Intern. J. Rem. Sensing, 16:2539-2553.

Morton R.A. 1996. Geoindicators os coastal wetlands and shorelines. In: A.R. Berger \& W.J. Iams (ed.). Geoindicators: assessing rapid environmental changes in earth systems. Rotterdam: A.A.Balkema, p. $207-230$.

Nordstrom K.F. 1980. Cyclic and seasonal beach response: a comparison of oceanside and bayside beaches. Phys. Geography (1-2):177-196.
Prost M.T., Mendes A.C., Faure J-F., Berredo J.F., Sales M.E.C., Furtado L.G., Silva M.G.S., Silva C.A., Nascimento I., Gorayeb I., Secco M.F.V., Luz L.M. 2001. Manguezais e estuários da costa paraense: exemplo de estudo multidisciplinar integrado (Marapanim e São Caetano de Odivelas) In: M.T. Prost \& A.C. Mendes (ed.). Ecossistemas costeiros: impactos e gestão ambiental. Belém: Museu Paraense Emílio Goeldi, p. 75-87.

Santos V.F. dos. 2000. Dinâmica de formação de cristas praiais na planície costeira da ilha de Algodoal - Nordeste do Pará, Brasil. In: Workshop ECOLAB, 5, Macapá, Boletim de Resumos, 129-133.

Souza Filho P.W.M. 2000a. Mangroves as geological indicator of coastal changes in Bragança, Pará, Northern Brazil. Mangrove 2000 Conference, Recife, Full Papers, CDROM.

Souza Filho P.W.M. 2000b. Avaliação e aplicação de sensores remotos no estudo de ambientes costeiros tropicais úmidos, Bragança, norte do Brasil. Tese de Doutorado, Centro de Geociências, Universidade Federal do Pará, 236 p.

Souza Filho P.W.M. \& Paradella W.R. 2002. Recognition of the main geobotanical features in the Bragança Mangrove Coast (Brazilian Amazon Region) from Landsat TM and RADARSAT-1 data. Wetlands Ecology and Management, 10:123-132.

Manuscrito SR-16 Recebido em 17 de novembro de 2002 Revisão dos autores em 06 de março de 2003 Revisão aceita em 20 de abril de 2003 